\title{
A study of incidence and risk factors of Surgical site infection following orthopedic surgical procedure in a tertiary care hospital in south India
}

\author{
Ali Mohammed P1 ${ }^{1}$, Deep Sharma ${ }^{2}$, K K Patro ${ }^{3}$, Jagdish Menon ${ }^{4}$, Murali Poduval ${ }^{5}$ \\ ${ }^{1}$ Dr Ali Mohammed P, Senior Resident, ${ }^{2}$ Dr Deep Sharma, Associate Professor, ${ }^{3}$ Dr D K Patro, Senior Professor, ${ }^{4}$ DR \\ Jagdish Menon, Professor \& Head, Department of orthopaedics, ${ }^{5}$ Dr Murali Poduval, Associate Professor, All are \\ affiliated with Department of orthopaedics, Jawaharlal Institute of Postgraduate Medical Education and Research \\ Pondicherry( JIPMER) Pondicherry, India
}

Address for Correspondence: Dr Ali Mohammed P., Email: dralinisreenmohammedp@gmail.com, No 32, Thiruvalluvar Street, Dr Radhakrishna Nagar, Pondicherry, India.

\begin{abstract}
Introduction: Surgical site infection following orthopaedic surgeries is a particularly catastrophic complication. So identification and stratification of risk factors of surgical site infection is utmost important in implementation of measures to prevent surgical site infection. Materials and Methods: This study was done in JIPMER Puducherry between January 2013 and August 2014. We aimed at identifying the incidence of surgical site infection and also tried to find out the factors associated with a higher risk for SSI. We studied a total of 249 patients, and collected their demographic data as per our proforma and at the end of the study data was compared among two groups of patients (patients with SSI vs Patients without SSI). Results: We found in our study that the incidence of patients developing surgical site infection as $11.6 \%$ (29 patients). BMI ( $>25$ ), use of $\mathrm{C}$ arm, duration of surgery ( $>3$ hours), duration of closed suction drain ( $>2$ days) and amount of collection of drain $(>170 \mathrm{ml})$ are risk factors of post-operative wound discharge and infection. Conclusion: The present study shows that incidence of surgical site infection in our patient population is $11.6 \%$, and out of various parameters studied we found that, BMI, use of C-arm, blood transfusion, duration of closed suction drain and amount of collection in suction drain to be important risk factors for the development of surgical site infection
\end{abstract}

Key words: Surgical site infection, risk factors, orthopedic surgeries

\section{Introduction}

Surgical site infection can be catastrophic in patients after orthopedic surgery as infection leads, to prolonged hospital stay and other complications [1]. Healthcare associated infections are very common in hospital ward especially surgical wards [2] and it imparts a high burden on health care system and on patients $[2,3]$ in view of mortality, morbidity, increased duration of hospital admission and also in terms of extra cost of treatment [4]. Surgical site infections are found to be second most common hospital acquired infection after asymptomatic bacteriuria [5].

Jadranka Maksimovic et al concluded that surgical site infection is associated with hyperglycemia, compound

Manuscript received: $4^{\text {th }}$ Sept 2015

Reviewed: $19^{\text {th }}$ Sept 2015

Author Corrected: $28^{\text {th }}$ Septt 2015

Accepted for Publication: $16^{\text {th }}$ Oct 2015 fracture, increased number of persons in theatre, amount and drainage duration, contaminated wounds, and co morbidities [6]. As we know that surgical site infection is a nightmare for an orthopedic surgeon, the identification of factors which most often leads to post operative complication is extremely important. In this context this study was done in JIPMER Puducherry between January 2013 and August 2014. We aimed at identifying the incidence of surgical site infection and also tried to find out the factors associated with a higher risk for SSI in a group of patients who had undergone clean elective orthopedic surgical procedure We also aim to create awareness among health professionals about risk factors of SSI, so that they can implement methods to prevent occurrence of SSI. 


\section{Aims \& Objectives}

1. To determine the incidence of surgical site infection following orthopaedic surgery in our patient population.

2. To assess the risk factors for the development of surgical site infection following orthopedic surgery

\section{Materials \& Methods}

This study was done in JIPMER (Jawaharlal institute of post-graduate medical education and research), Pondicherry, a tertiary care hospital. Those patients who had undergone clean elective orthopedic surgical procedure were included in this study. It was a prospective study and was carried out from September 2012 to June 2014. Study approval was obtained from the institute PG thesis review meeting and ethical clearance was obtained from the Institute Ethics Committee of JIPMER. The purpose and details of the study protocol was explained to the subjects and informed consent was obtained.

The study comprised of a single study group of two hundred and forty nine patients. Subjects were enrolled into the study based on the following inclusion and exclusion criteria.

(i) Inclusion criteria

1. All patients undergoing any clean elective orthopedic surgical procedure were included in the study.

(ii) Exclusion criteria

1. Those patients who failed to consent for inclusion in study,

2. Those patients who had some other known source of infection (respiratory or urinary infection) or any other septic foci.

3. Those patients who deviated from our study protocol.

4. Known immune deficiency state.

5. Proven pre-op infection.

All patients who satisfy our inclusion criteria were followed up during study period according to the existing departmental protocol for antibiotic prophylaxis, pre operative preparation and post operative wound care. Pre operative patient preparation was started by scrubbing with chlorhexidine followed by application of a sterile towel two days prior to surgery and the day of surgery.

The epidemiological factors for all the patients were noted as per the attached proforma. Any patient who developed a serous discharge from the wound site or presented with signs of inflammation like warmth, redness, induration at the operative site was further evaluated for the presence of surgical site infection. Wound swab was taken and sent for Gram stain along with pyogenic cultures, All the routine clinical and hematological work up were done to look for signs of infection including 4 hourly temperature chart, pulse charting, complete hemogram with peripheral smear, ESR and CRP levels. Other potential sites of infection such as respiratory and urinary tract infections were ruled out by appropriate clinical examination and lab investigations. All the patients were followed up till surgical wound healing and all the patients with wound complication and surgical site infection were noted.

Statistical Analysis: It was a prospective study. Chi square or fisher's exact test for comparing the categorical variables and logistic regression analysis was used to identify the independent factors associated with surgical site infection. AII statistical analysis was carried out at $5 \%$ level of significance and a $\mathrm{p}$ value < 0.05 was considered significant and results were drawn.

\section{Observation}

\begin{tabular}{|l|l|l|}
\hline Infection & Frequency & Percent \\
\hline Surgical site infection & 29 & 11.6 \\
No wound discharge and normal wound healing(control group) & 220 & 88.4 \\
\hline Total & $\mathbf{2 4 9}$ & $\mathbf{1 0 0 . 0}$ \\
\hline
\end{tabular}

Statistical Analysis: Various parameters were compared among patients using chi square test as given below. 
Table No 1: Demographic parameters and SSI

\begin{tabular}{|c|c|c|c|c|c|c|c|c|c|c|c|c|}
\hline & & \multicolumn{4}{|c|}{ Surgical site infection } & & \multirow{3}{*}{$\chi^{2}$} & \multirow{3}{*}{ Df } & \multirow{3}{*}{$\mathrm{P}$} & \multirow{3}{*}{ OR } & \multirow{2}{*}{\multicolumn{2}{|c|}{$95 \% \mathrm{CI}$}} \\
\hline & & \multicolumn{2}{|c|}{ Present } & \multicolumn{2}{|c|}{ Absent } & & & & & & & \\
\hline & & $\mathrm{N}$ & $\%$ & $\mathrm{~N}$ & $\%$ & $\mathrm{~N}$ & & & & & Lower & Upper \\
\hline \multirow[t]{2}{*}{ Age } & $\leq 45$ & 15 & 10.4 & 129 & 89.6 & 144 & \multirow[t]{2}{*}{.502} & \multirow[t]{2}{*}{1} & \multirow[t]{2}{*}{.479} & & & \\
\hline & $>45$ & 14 & 13.3 & 91 & 86.7 & 105 & & & & & & \\
\hline \multirow[t]{2}{*}{ Sex } & Male & 17 & 10.2 & 150 & 89.8 & 167 & \multirow[t]{2}{*}{1.060} & \multirow[t]{2}{*}{1} & \multirow[t]{2}{*}{.303} & & & \\
\hline & Female & 12 & 14.6 & 70 & 85.4 & 82 & & & & & & \\
\hline
\end{tabular}

There is no significant difference in two groups of patients with/without surgical site infection in terms of age and sex.

Table No 2: Preoperative risk factors \& SSI

\begin{tabular}{|c|c|c|c|c|c|c|c|c|c|c|c|c|}
\hline & & \multicolumn{4}{|c|}{ Surgical site infection } & \multirow{3}{*}{$\mathrm{N}$} & \multirow{3}{*}{$X^{2}$} & \multirow{3}{*}{ Df } & \multirow{3}{*}{$\mathrm{P}$} & \multirow{3}{*}{ OR } & \multicolumn{2}{|c|}{$95 \% \mathrm{CI}$} \\
\hline & & \multicolumn{2}{|c|}{ present } & \multicolumn{2}{|c|}{ absent } & & & & & & Lower & Upper \\
\hline & & $\mathrm{N}$ & $\%$ & $\mathrm{~N}$ & $\%$ & & & & & & & \\
\hline \multirow[t]{2}{*}{ BMI } & $\geq 25$ & 9 & 45 & 11 & 55 & 20 & \multirow[t]{2}{*}{23.510} & \multirow[t]{2}{*}{1} & \multirow[t]{2}{*}{.000} & \multirow[t]{2}{*}{8.550} & \multirow[t]{2}{*}{3.167} & \multirow[t]{2}{*}{23.084} \\
\hline & $<25$ & 20 & 8.7 & 209 & 91.3 & 229 & & & & & & \\
\hline \multirow[t]{3}{*}{ ASA2 } & $\begin{array}{l}\text { Grade } 2 \\
\text { or } 3\end{array}$ & 8 & 14.8 & 46 & 85.2 & 54 & \multirow[t]{2}{*}{.673} & \multirow[t]{2}{*}{1} & \multirow[t]{2}{*}{.412} & & & \\
\hline & Grade 1 & 21 & 10.8 & 174 & 89.2 & 195 & & & & & & \\
\hline & Present & 14 & 10.4 & 121 & 89.6 & 135 & \multirow{3}{*}{.467} & \multirow{3}{*}{1} & \multirow{3}{*}{.495} & & & \\
\hline \multirow{2}{*}{ Trauma } & Absent & 15 & 13.2 & 99 & 86.8 & 114 & & & & & & \\
\hline & Absent & 23 & 10.1 & 204 & 89.9 & 227 & & & & & & \\
\hline Arthroplasty & Present & 4 & 15.4 & 22 & 84.6 & 26 & \multirow[t]{2}{*}{.093} & \multirow[t]{2}{*}{1} & \multirow[t]{2}{*}{.760} & & & \\
\hline \multirow{2}{*}{ Deformity } & Absent & 25 & 11.2 & 198 & 88.8 & 223 & & & & & & \\
\hline & Present & 1 & 4.3 & 22 & 95.7 & 23 & \multirow[t]{2}{*}{0.647} & \multirow[t]{2}{*}{1} & \multirow[t]{2}{*}{.421} & & & \\
\hline \multirow{3}{*}{ Malignancy\&Others } & Absent & 28 & 12.4 & 198 & 87.6 & 226 & & & & & & \\
\hline & Present & 4 & 9.5 & 38 & 90.5 & 42 & \multirow[t]{2}{*}{.043} & \multirow[t]{2}{*}{1} & .836 & & & \\
\hline & Absent & 25 & 12.1 & 182 & 87.9 & 207 & & & & & & \\
\hline
\end{tabular}

BMI $>25$ is found to be significant pre-operative risk factor for the development of SSI.

Table No 3: Risk factors during surgery and SSI

\begin{tabular}{|c|c|c|c|c|c|c|c|c|c|c|c|c|}
\hline & & \multicolumn{4}{|c|}{ Surgical site infection } & \multirow{3}{*}{$\mathrm{N}$} & \multirow{3}{*}{$X^{2}$} & \multirow{3}{*}{ Df } & \multirow{3}{*}{$\mathrm{P}$} & \multirow{3}{*}{ OR } & \multirow{2}{*}{\multicolumn{2}{|c|}{$95 \% \mathrm{CI}$}} \\
\hline & & \multicolumn{2}{|c|}{ present } & \multicolumn{2}{|c|}{ absent } & & & & & & & \\
\hline & & $\mathrm{N}$ & $\%$ & $\mathrm{~N}$ & $\%$ & & & & & & Lower & Upper \\
\hline \multirow[b]{2}{*}{$\begin{array}{l}\text { Method of hair } \\
\text { removal }\end{array}$} & PSRW & 25 & 13.2 & 165 & 86.8 & 190 & \multirow[b]{2}{*}{1.780} & \multirow[b]{2}{*}{1} & \multirow[b]{2}{*}{.182} & & & \\
\hline & $\begin{array}{l}\text { Not done or } \\
\text { Shaving on } \\
\text { the table }\end{array}$ & 4 & 6.8 & 55 & 93.2 & 59 & & & & & & \\
\hline \multirow[t]{2}{*}{ No of assistants } & $\geq 3$ & 27 & 12.2 & 195 & 87.8 & 222 & \multirow[t]{2}{*}{.590} & \multirow[t]{2}{*}{1} & \multirow[t]{2}{*}{.443} & & & \\
\hline & $<3$ & 2 & 7.4 & 25 & 92.6 & 27 & & & & & & \\
\hline \multirow[t]{2}{*}{ Use of C-Arm } & Present & 20 & 15.6 & 108 & 84.4 & 128 & \multirow[t]{2}{*}{4.052} & \multirow[t]{2}{*}{1} & \multirow[t]{2}{*}{.044} & \multirow[t]{2}{*}{2.305} & \multirow[t]{2}{*}{1.005} & \multirow[t]{2}{*}{5.285} \\
\hline & Absent & 9 & 7.4 & 112 & 92.6 & 121 & & & & & & \\
\hline \multirow{2}{*}{$\begin{array}{l}\text { Use of fracture } \\
\text { table }\end{array}$} & Present & 7 & 20 & 28 & 80 & 35 & \multirow{2}{*}{2.762} & \multirow{2}{*}{1} & \multirow{2}{*}{.097} & & & \\
\hline & Absent & 22 & 10.3 & 192 & 89.7 & 214 & & & & & & \\
\hline Indwelling & Present & 14 & 16.5 & 71 & 83.5 & 85 & 2.919 & 1 & .088 & & & \\
\hline
\end{tabular}




\begin{tabular}{|c|c|c|c|c|c|c|c|c|c|c|c|c|}
\hline $\begin{array}{l}\text { urinary } \\
\text { catheter }\end{array}$ & Absent & 15 & 9.1 & 149 & 90.9 & 164 & & & & & & \\
\hline \multirow{2}{*}{$\begin{array}{l}\text { Blood } \\
\text { transfusion }\end{array}$} & Yes & 8 & 30.8 & 18 & 69.2 & 26 & \multirow{2}{*}{10.317} & \multirow{2}{*}{1} & \multirow{2}{*}{.001} & \multirow{2}{*}{4.275} & \multirow{2}{*}{1.659} & \multirow{2}{*}{11.014} \\
\hline & No & 21 & 9.4 & 202 & 90.6 & 223 & & & & & & \\
\hline \multirow[t]{3}{*}{ Site } & Upper limb & 4 & 6.8 & 55 & 93.2 & 59 & \multirow[t]{3}{*}{6.597} & \multirow[t]{3}{*}{2} & \multirow[t]{3}{*}{.037} & & & \\
\hline & Lower limb & 19 & 11.3 & 149 & 88.7 & 168 & & & & & & \\
\hline & Spine & 6 & 27.3 & 16 & 72.7 & 22 & & & & & & \\
\hline
\end{tabular}

Result: Use of C arm, blood transfusions are found to be post-operative risk factors of SSI.

Table No 4: Post operative risk factors and SSI

\begin{tabular}{|c|c|c|c|c|c|c|c|c|c|c|c|c|}
\hline & & \multicolumn{4}{|c|}{ Surgical site infection } & \multirow{3}{*}{$\mathrm{N}$} & \multirow{3}{*}{$X^{2}$} & \multirow{3}{*}{ Df } & \multirow{3}{*}{$\mathrm{P}$} & \multirow{3}{*}{ OR } & \multirow{2}{*}{\multicolumn{2}{|c|}{$95 \% \mathrm{CI}$}} \\
\hline & & \multicolumn{2}{|c|}{ present } & \multicolumn{2}{|c|}{ absent } & & & & & & & \\
\hline & & $\mathrm{N}$ & $\%$ & $\mathrm{~N}$ & $\%$ & & & & & & Lower & Upper \\
\hline \multirow{2}{*}{$\begin{array}{l}\text { Post op FBS } \\
(\mathrm{mg} / \mathrm{dL})\end{array}$} & $>110$ & 4 & 2 & 13 & 76.5 & 17 & \multirow[t]{2}{*}{2.504} & \multirow[t]{2}{*}{1} & \multirow[t]{2}{*}{.114} & & & \\
\hline & $<110$ & 25 & 10.8 & 207 & 89.2 & 232 & & & & & & \\
\hline \multirow{2}{*}{$\begin{array}{l}\text { Amount } \\
\text { collection } \\
\text { drain }\end{array}$} & $\geq 170$ & 8 & 29.6 & 19 & 70.4 & 27 & \multirow[b]{2}{*}{9.517} & \multirow[b]{2}{*}{1} & \multirow[b]{2}{*}{.002} & \multirow[b]{2}{*}{4.030} & \multirow[b]{2}{*}{1.574} & \multirow[b]{2}{*}{10.321} \\
\hline & $<170$ & 21 & 9.5 & 201 & 90.5 & 222 & & & & & & \\
\hline \multirow{2}{*}{$\begin{array}{l}\text { No days } \\
\text { ( drain) }\end{array}$} & $>2$ & 9 & 30.0 & 21 & 70.0 & 30 & \multirow{2}{*}{11.166} & \multirow{2}{*}{1} & \multirow{2}{*}{.001} & \multirow{2}{*}{4.264} & \multirow{2}{*}{1.723} & \multirow{2}{*}{10.553} \\
\hline & $<2$ & 20 & 9.1 & 199 & 90.9 & 219 & & & & & & \\
\hline \multirow{2}{*}{$\begin{array}{l}\text { Post op } \\
\text { duration of } \\
\text { stay in days }\end{array}$} & $>18$ & 20 & 55.6 & 16 & 44.4 & 36 & \multirow[b]{2}{*}{78.851} & \multirow[b]{2}{*}{1} & \multirow[b]{2}{*}{.000} & \multirow[b]{2}{*}{28.333} & \multirow[b]{2}{*}{11.102} & \multirow[b]{2}{*}{72.310} \\
\hline & $<18$ & 9 & 4.2 & 204 & 95.8 & 213 & & & & & & \\
\hline \multirow{2}{*}{$\begin{array}{l}\text { Duration of } \\
\text { surgery in } \\
\text { hours }\end{array}$} & $>3$ & 20 & 17.4 & 95 & 82.6 & 115 & \multirow[b]{2}{*}{6.853} & & & & & \\
\hline & $<3$ & 9 & 6.7 & 125 & 93.3 & 134 & & 1 & .009 & 2.924 & 1.274 & 6.710 \\
\hline
\end{tabular}

Large amount collection drain, No days( drain),Post op duration of stay in days, Duration of surgery in hours are found to be risk factors of SSI.

It is also clear from the study that average duration of stay in hospital in patients with SSI is 23 days as compared to 12 days in patients without surgical site infection (with a $\mathrm{p}$ value of 0.00 ).

\section{Discussion}

Surgical site infection (SSI) is a complication causing excessive morbidity to the patient,high chance of reoperations, use of antibiotics for longer duration with its side effects, pain,and increased economic burden to the patient as well as health care system [1]. Majority of surgical site infections are said to be happened at the time of surgical procedure[7]. This fact was very well reinforced by decreased rate of infection by execution of infection prevention strategies focussed towards practices during surgery inside operation theatre.However,there is no study which will depict actual infection rate acquired at the time of surgical procedure in the operating theatre versus during postoperative period in the ward [8]. 
In our study we found that the incidence of postoperative SSI after clean elective orthopedic surgical procedure was $11.6 \%$, this is in contrast to incidence of surgical site infection of $2 \%$ in developed countries [9]. The higher incidence of surgical site infection in our study may be due to the lack of economic assets, obsolescent instruments and improper ventilation in our operating theater, as well as incomplete solicitation of infection prevention stratagies.

We looked at various parameters which could be a cause for occurrence of surgical site infections. We analyzed the data and compared these characteristics between patients who developed wound discharge with evidence of infection and those which showed normal wound healing. It was found in our study that BMI, use of $\mathrm{C}$ arm, blood transfusion, duration and amount of collection of post-operative closed suction drain, duration of surgery were significant risk factors for the development of surgical site infection in the postoperative period.

Also On reviewing the literature we found comparable results in some of the previous studies. BMI $(>25)$, use of $\mathrm{C}$ arm, duration of surgery ( $>3$ hours), duration of closed suction drain( $>2$ days) and amount of collection of drain $(>170 \mathrm{ml})$, are risk factors of post-operative wound discharge and infection $[10,11,12]$.

BMI is found to be a significant risk factor for development of wound complication if BMI is $>25$ with a $\mathrm{p}$ value of 0.000 and OR of 8.55 , this fact has also been proved by Ridgeway et al [10]. This is in contrast to $\mathrm{BMI}$ of $>30$ or $>35$ in western patient population. This lower value of BMI as a risk factor for SSI as compared to western population may be due to average low BMI of our patient population. The use of ' $\mathrm{C}$ arm' is found to be another potential risk factor leading to post-operative wound complications with a $\mathrm{p}$ value of 0.044 and OR of $2.305[11,12]$. This can be explained due to lack of frequent draping during surgical procedure with each rotation of $\mathrm{C}$ arm.

It is apparent in our study that peri-operative blood transfusion is a risk factor for the development of postoperative complications from those without blood transfusion with a $\mathrm{P}$ value of 0.001 and $\mathrm{OR}$ of 4.275. This fact also has been observed by various studies $[13,14]$ revealing that allogenic blood transfusion will cause increased perioperative complications. However there are studies which shows conflicting result on this matter $[15,16]$.

In day to day practice we usually keep suction drain at surgical site in order to prevent haematoma and SSI but this practice is also a matter of debate as seen in various studies $[4,17,18,19,20,21]$.In our study we have found that there is increased chance of wound discharge if amount of collection is $>170 \mathrm{ml}(\mathrm{p}-0.002)$ and suction duration is $>48$ hours $(\mathrm{p}-0.001)$.

It is evident in our study that higher chance of infection is associated with Increased duration of surgery ( $>3$ hours-P value of 0.009 and OR of 2.924). It can be attributed to exposure of operative site to environment for longer duration. This information has already has been given by Mangran AJ et al [22]

This study illustrates that, not only patient specific elements are responsible, but procedure and post procedure related factors are also responsible for surgical site infection and complications

Our study has certain limitations as there is no clear cut protocol for surveillance and follows up of patients who are getting discharged from our institute. Because of this, patients developed SSI after discharge may not be included in our study. Secondly our study comprises a small sample size, so further randomized trials with larger sample size are recommended.

\section{Conclusion}

This study had shown that incidence of surgical site infection in our patient population was $11.6 \%$, and out of various demographic parameters studied it was found that BMI, use of C-arm, blood transfusion, duration of closed suction drain and amount of collection in suction drain were found to be risk factors for post-operative wound discharge and complications.

\section{Funding: Nil \\ Conflict of interest: None. \\ Permission of IRB: Yes}

\section{References}

1. Merle V, Germain J.M, Chamouni P, Daubert .Assessment of prolonged hospital stay attributable to surgical site infections using appropriateness evaluation protocol. Am J Infect cont.2000;28(2): 109-15. 
2. Mangram AJ, Horan TC, Pearson ML, Silver LC, Jarvis WR. Guideline for prevention of surgical site infection. Hospital Infection Control Practices Advisory Committee. Infect. Control Hosp. Epidemiol.1999;20:250-278.

3. Prokuski L. Prophylactic antibiotics in orthopaedic surgery. J Am Acad Orthop Surg.2008; 16:283-293.

4. Broex EC, van Asselt AD, Bruggeman CA, van Tiel FH. Surgical site infections, how high are the costs?. $J$. Hosp. Infect.2009;72:193-201.

5. Pittet D, Harbarth S, Ruef C et al. Prevalence and risk factors for nosocomial infections in four university hospitals in Switzerland. Infect Control Hosp. Epidemiol. 1999;20:37-42.

6. Jadranka Maksimovic, Ljiljana Markovic-Denic, Marko Bumbasirevic, Jelena Marinkovic, Hristina Lajinac.Surgical site infections in orthopedic patients. Prospective cohort study.2008;49:58-65.

7. Ayliffe GA. Role of the environment of the operating suite in surgical wound infection. Rev. Infect. Dis. 1991;13:800-804.

8. Ilker,Uckay,Stephan Harbarth,Robin Peter,Daniel Lew,Pierre Hoffmeyer,Didier Pittet. Preventing Surgical Site Infections.Expert Rew Anti Infect Ther. 2010; 8(6):657-670

9. Pull ter,Gunne AF, Cohen DB. Incidence, prevalence, and analysis of risk factors for surgical site infection following adult spinal surgery.Spine.2009;34(13):14228 .

10. Ridgeway S, Wilson J, Charlet A, Kafatos G, Pearson A, Coello R. Infection of the surgical site after arthroplasty of the hip.J Bone Joint Surg Br.2005;87(6):844-50.

11. Peters PG, Laughlin RT, Markert RJ, Nelles DB, Randall KL, Prayson MJ. Timing of C-arm drape contamination.Surg Infect. 2012;13(2):110-3.

12. Kaska.A standardized and safe method of sterile field maintenance during intra-operative horizontal plane fluoroscopy. Patient Safety in Surgery;2010:4-20.

13. Heiss MM, Mempel W, Jauch KW, et al. Beneficial effect of autologous blood transfusion on infectious complications after colorectalcancer surgery. Lancet.1993; 342:1328-1333.

14. Jensen LS, Andersen AJ, Christiansen PM, et al. Postoperative infection and natural killer cell function following blood transfusion in patients undergoing elective colorectal surgery. Br J Surg.1992; 79:513-516.

15. Talbot TR, D'Agata EMC, Brinsko V, Lee B, Speroff T, Schaffner W. Perioperative blood transfusion is predictive of poststernotomy surgical site infection.marker for morbidity or true immunosuppressant? Clin Infect Dis Off Publ Infect Dis Soc Am. 2004;38(10):1378-82.

16. Vamvakas EC, Moore SB, Cabanela M. Blood transfusion and septic complications after hip replacement surgery. Transfusion (Paris).1995;35(2):150-6.)

17. R. Clifton, S.Haleem, A. McKee,M. J. Parker. Closed suction surgical wound drainage after hip fracture surgery.a systematic review and meta-analysis of randomized controlled trials: international Orthopaedics december 2008;32(6): 723-727.

18. Martyn J Parker, Vicki Livingstone, Rupert Clifton, Andrew McKee. Closed suction surgical wound drainage after orthopedic surgery.2007;4:4-5.

19. Qi-dong Zhang,MD,Wan-shou Guo, MD,Qian Zhang, PhD,Zhao-hui Liu, MD,Li-ming Cheng, MD,Zirong Li, MD.Comparison Between Closed Suction Drainage and Nondrainage in Total Knee Arthroplasty.The Journal of Arthroplasty .2011;26(8):1265-1272.

20. Margaret A. Olsen, Jeffrey J. Nepple, K. Daniel Riew, Lawrence G. Lenke, Keith H. Bridwell, Jennie Mayfield and Victoria J. Fraser. Risk Factors for Surgical Site Infection Following Orthopedic Spinal Operations.J Bone Joint Surg Am.2008; 90:62-69.

21. Lilani SP,Jangale N,Chowdhary A,Daver GB.Surgical site infection in clean and clean contaminated cases. Indian J Medical Microbiology.2005; 23(4):249-252.

22. Mangran AJ, Horan TC, Pearlson ML, Silver LC, Jarvis WR. Guideline for prevention of surgical site infection 1999. Infect Control Hosp Epidemiol. 1999; 20:247-278. 


\section{How to cite this article?}

Ali Mohammed P, Deep Sharma, D K Patro, Jagdish Menon, Murali Poduval. A study of incidence and risk factors of Surgical site infection following orthopedic surgical procedure in a tertiary care hospital in south India . Int J Med Res Rev 2015;3(9):983-989. doi: 10.17511/ijmrr.2015.i9.182. 